\title{
Structural BMPs for Stormwater Treatment Control - a Performance Based Design Method for Urban Drainage System
}

\author{
Hong Lin, Walt Stein and Fariar Kohzad
}

Stormwater management has shifted focus to "starting from the source". The concepts of low impact development (LID), better site design and "smart growth," with the goal of producing site plans that reduce impervious areas and runoff volume, also address water quality. The LID based stormwater management program conveys the message that end of pipe structural Best Management Practices (BMPs) are the least desirable method for stormwater pollution controls, though these treatment BMPs play an important role. In the past decades, structures BMPs have been proven successful in controlling stormwater runoff pollution. However, their success is offset by a prevalence of inadequate and inconsistent design criteria, which have resulted in the selection and installation of units whose performance does not meet expectations, and the units ultimately fail to protect receiving water bodies and aquatic environment from stormwater pollution to the degree intended. This chapter intends to demonstrate performance-based hydrology design methods for structure BMP, specifically the flow-through stormwater treatment unit (SWTU).

Lin, H., W. Stein and F. Kohzad. 2009. " Structural BMPs for Stormwater Treatment Control - a Performance Based Design Method for Urban Drainage System." Journal of Water Management Modeling R235-17. doi: 10.14796/JWMM.R235-17.

(C) CHI 2009 www.chijournal.org ISSN: 2292-6062 (Formerly in Conceptual Modeling of Urban Water Systems. ISBN: 978-0-9808853-2-3) 


\subsection{Storm Hydrology}

Understanding storm hydrology is critical for urban drainage design and stormwater management. The conveyance systems are typically designed to handle large storms (10-year to 25 -year storm events) in urban drainage design. The infrequent large storms may carry a large amount of pollutant in a single event, but the contribution to the annual average pollution load is less significant, due to the infrequency of occurrence. Therefore, when designing flow-through SWTU, treatment of the water quality storm which is small to medium, with a return frequency less than two-year, is considered sufficient. In addition, it has been realized that small storms (with frequency less than six months) are contributing to most annual urban runoff. Consequently, flow-through SWTU can be designed to address the runoff flows from those small events instead of treating the large conveyance flow or the drainage design capacity. The water quality treatment flow can be determined using various hydrology methods.

\subsection{Performance Requirement}

In flow-through SWTU design, performance requirements should be established because the ultimate goal of stormwater management using these BMPs is to size the SWTU to meet specific performance requirements with regard to pollutant removal.

\subsubsection{Unit Operation and Performance Evaluation}

A flow-through SWTU removes particulates and associated contaminants from stormwater runoff through physical separation of particulates from the aqueous phase by either gravity settling, screening/deflecting/baffling, and/or filtration. The performance of this type of system is typically evaluated by particulate removal, measured and characterized by analytical parameters such as total suspended solids (TSS) or suspended sediment concentration (SSC). Evaluation of a manufactured flow-through system has shown that the system performance is a function of particle size, influent concentration, specific gravity, water temperature and flow rate. The removal efficiency increases with the increased particle size, increased influent concentration, increased specific gravity, increased temperature and reduced operation rate. 


\subsubsection{Particle Size Distribution (PSD)}

Based on the fundamentals of the unit process, particle size is a critical factor in SWTU performance evaluation. Some research studies (Kobriger 1984, Ball and Abustan 1995, Characklis and Wiesner 1998, Li, et al 2005) reported pollutants are associated with fine particles $(<75-\mu \mathrm{m})$ in urban runoff, while others (Sartor and Boyd 1972, Shaheen 1975, Sansalone 1997, 1998) reported dominance of medium to coarse size particles in the runoff from the studied watershed. Regulations currently focus on the removal of the fine particles and associated pollution. In the meantime, the benefits of removing large size particles prior to infiltration or filtration systems are recognized and pretreatment is encouraged to improve life-cycle performance and reduce the maintenance cost for those systems.

The New Jersey Department of Environmental Protection (DEP) has specified a U.S.D.A. sandy loam TSS gradation for laboratory testing of the manufactured treatment system. This specified gradation has a mean particle size $\mathrm{d}_{50}$ of approximately $67-\mu \mathrm{m}$. In western Washington, field data show most TSS particles are smaller than $125-\mu \mathrm{m}$ (Ecology, 2004). Therefore, Washington State Department of Ecology (WSDOE)'s guidance for evaluating emerging stormwater treatment technologies - Technology Assessment Protocol of Ecology (TAPE) has recommended U.S. Silica Sil-Co-Sil 106 ground silica to be used as a typical PSD for lab testing. Sil-Co-Sil 106 represents a very fine gradation with mean particle size less than 20 microns. The City of Indianapolis (Indy) and some other agencies in the US have required the use of the OK-110 silica sand as the standard test material in its evaluation criteria for a manufactured stormwater quality treatment unit.

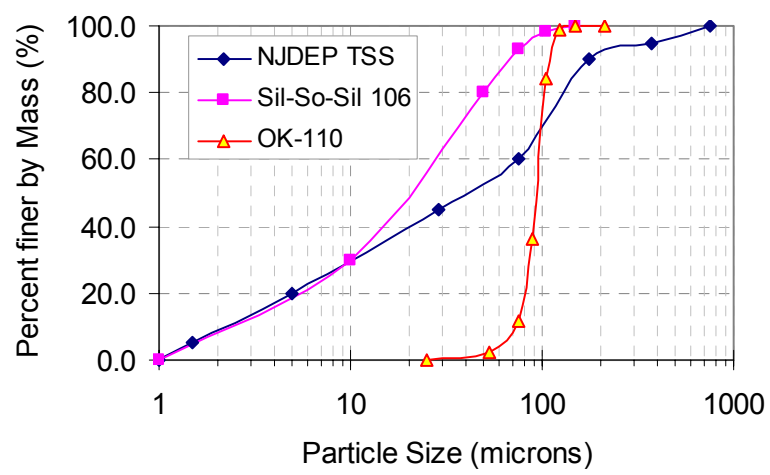

Figure 17.1 Particle size distribution comparisons (NJDEP, WASDOE, Indy). 
Figure 17.1 compared the PSDs of the TSS materials defined in the above referenced protocols. As shown, Sil-Co-Sil 106 represents a very fine gradation; OK-110 represents a coarser gradation, and NJDEP TSS gradation covers a wider range of particles.

The above materials and PSD gradations are most often used in the product evaluation and reports of the manufactured stormwater treatment units in the United States. Figure 17.2 shows the modeled performance of a manufactured BMP device for these three different PSDs.

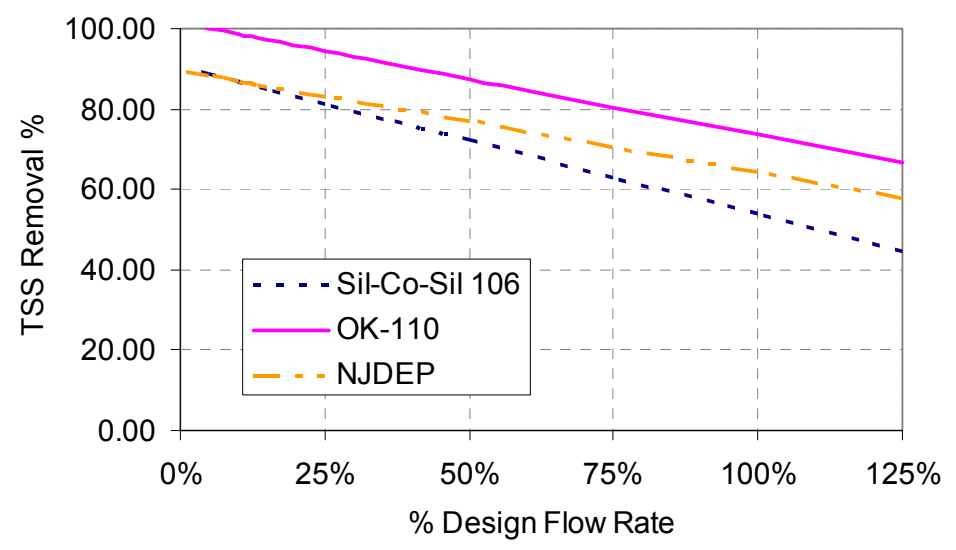

Figure 17.2 Performance prediction of a proprietary HDS device for various PSDs under typical influent TSS and room temperature $20^{\circ} \mathrm{C}$.

As shown, the performance determined by TSS removal varies from $48 \%$ up to $77 \%$ at $100 \%$ design flow rate.

In evaluating or comparing performances of various technologies or devices, particle size distribution of the pollutants should be clearly defined, either using $\mathrm{d}_{50}$ (mean particle size), the Hazen uniformity coefficient or a typical lab test material (i.e. U.S. Silica Sand). The performance standards should be established for a recommended PSD, preferably a consistent testing material for lab testing of SWTU.

Other factors such as influent solid concentration, specific gravity and temperature should also be considered in the performance guideline. Typical influent TSS concentration in urban stormwater runoff is less than $300-\mathrm{mg} / \mathrm{L}$. Most of the lab testing is conducted under room temperature. In evaluating or predicting system performance, these factors should be taken into account. For example, the SWTU reported higher removal percent with higher influent concentration may not be as effective as the SWTU with 
lower removal percent but with testing of lower influent TSS. For instance, "A" device claims an $80 \%$ TSS removal, and it seems to be performing better than "B" device with a reported 50\% TSS removal only. However, "A" device was tested using an influent TSS concentration of $1000-\mathrm{mg} / \mathrm{L}$. The effluent quality from " $A$ " device is $200-\mathrm{mg} / \mathrm{L}$. In comparison, "B" device was tested using an influent TSS concentration of $100-\mathrm{mg} / \mathrm{L}$. Even with $50 \%$ removal, the effluent quality of "B" device is $50-\mathrm{mg} / \mathrm{L}$. From an effluent water quality perspective, the "B" device outperforms the " $\mathrm{A}$ " device. Therefore, percent removal alone is considered an inadequate evaluation criterion (Jones et. al, 2008).

Instead, effluent quality and mass removal of pollutants are recommended to be used for the evaluation of BMP performance. In cold climate conditions, solid separation and performance from the SWTU may not be as claimed, due to the temperature differences in the field compared to the lab testing. (De Ridder et al. 2007). These factors should be considered in establishing performance criteria.

\subsection{Maximum Hydraulic Loading Rate}

The maximum hydraulic loading (overflow loading rate) of a settling basin is determined to be $1.34-\mathrm{lps} / \mathrm{m}^{2}\left(2-\mathrm{gpm} / \mathrm{ft}^{2}\right)$ (Metcalf \& Eddy, 2003). Hydraulic maximum loading rate limits for Swirl/Vortex type units have been employed by a few storm water management agencies in the United States as shown in Table 17.1.

Table 17.1 Guidance on the maximum hydraulic loading rates for vortex type SWTU.

\begin{tabular}{ll}
\hline Hydraulic loading rates & Governing agency \\
\hline $23.53-\mathrm{lps} / \mathrm{m}^{2}$ & Peak loading rate during water quality storm event \\
$\left(35-\mathrm{gpm} / \mathrm{ft}^{2}\right)$ & regulated by Washington State Department of \\
& Ecology's Technical Review and Approval \\
& Committee \\
& Section MP-51, Stormwater Best Management \\
$16.14-\mathrm{lps} / \mathrm{m}^{2}$ & Handbook, New and Redevelopment Handbook, \\
$\left(24-\mathrm{gpm} / \mathrm{ft}^{2}\right)$ & California Stormwater Quality Association \\
& (CASQA) \\
\hline
\end{tabular}

Regulating a hydraulic loading rate will ensure appropriate design without causing scouring in the flow through a SWTU. 


\subsection{Hydrology Method and Performance-Based Hydrology Design for SWTU}

In urban drainage design, various hydrology methods can be used to estimate runoff volume. Engineers use a variety of software programs (such as HEC-HEM) to determine the 2-year, 10-year, and 100-year storms for the drainage system design.

As discussed above, the flow-through SWTU's performance is a function of operating rate. The operating rate or design flow is determined by the runoff flow. A performance-based design method requires SWTU sizing based on the hydrology analysis of the drainage area and the SWTU performance under various operating conditions. The performance requirement is typically "TSS removal under design flow rate", referring to "a point on a curve" or "Average Annual TSS removal". The following sections will provide a few design examples demonstrating the performance-based hydrology design.

The most commonly used hydrological method to determine the runoff flow from a site or drainage basin includes the Rational Method and the NRCS Runoff Curve Number Method. We have developed the Probabilistic Rational Method (PRM), the Probabilistic NRCS Method (P-NRCS) and the Rational Rainfall method for flow-through SWTU design.

Basic rational method (RM) is described in Equation (17.1):

where:

$$
\mathrm{Q}=\mathrm{CIA}
$$

$$
\begin{aligned}
\mathrm{Q} & =\text { flow } \\
\mathrm{C} & =\text { runoff coefficient }, \\
\mathrm{I} & =\text { rainfall intensity, and } \\
\mathrm{A} & =\text { drainage area size } .
\end{aligned}
$$

The intensity (I) is a function of time of concentration $\left(t_{c}\right)$ and $t_{c}$ is determined by a number of drainage area's parameters. In a simple form $t_{c}$ is a function of the drainage area size. Intensity can be found from IntensityDuration-Frequency (IDF) curves in either table or chart, or calculated from a formula. IDF information is extracted from historical rainfall data series after frequency analyses are conducted.

Runoff coefficient (C) represents the drainage area characteristics. Theoretically it is a discharge coefficient for overland flow. As such, the depth of flow or indirectly the intensity of the rain has an impact on this coefficient. Values of runoff coefficient for various land covers are provided in many hydrology textbook and stormwater design manuals (i.e. Lindeburg, 2006). 
When using the rational method, it is important that rainfall duration for the selected intensity equals the time of concentration for the site. Otherwise, the method could either over-estimate or under-estimate the flow. Due to this constraint, the rational method is recommended only for small homogeneous drainage areas up to 60 acres (24.28 ha).

\subsubsection{Uniform Intensity Approach - Simplified Rational Method for SWTU Design}

Based on small storm hydrology, water quality (WQ) treatment flow for a single intensity storm can be easily determined using the rational method. The following steps are used to obtain the WQ flow rate from the uniform intensity approach:

1. define a "small storm" for stormwater runoff management (three-month or six-month);

2. identify the intensity for this small storm (i.e. Uniform Intensity Approach $\mathrm{I}=0.2 \mathrm{in} / \mathrm{hr}$, California Stormwater BMP Handbook uniform standards);

3. determine the WQ flow using ration method equation (17.1);

4. select the structure BMPs with minimum treatment capacity equal to the WQ flow; and

5. verify the performance of the SWTU (if the performance does not meet the requirement, the unit needs to be resized or the SWTU selection needs to be reviewed).

\subsubsection{Probabilistic Rational Method (PRM)}

The Probabilistic Rational Method (PRM) is developed based on the basic rational method. The peak flow is computed for each return period as described by Equation (17.2):

where:

$$
\mathrm{Q}_{\mathrm{i}}=\mathrm{F}_{\mathrm{i}} \mathrm{C}_{10} \mathrm{I}_{\mathrm{i}} \mathrm{A}
$$

$$
\begin{aligned}
\mathrm{Q}_{\mathrm{i}}= & \text { flow for various individual storm events, } \\
\mathrm{F}_{\mathrm{i}}= & \text { runoff coefficient correction factor for various events, } \\
\mathrm{C}_{10}= & 10 \text {-year runoff coefficient, typically used in rational } \\
& \text { method, } \\
\mathrm{I}_{\mathrm{i}}= & \text { individual rainfall intensity for storm event, a } \\
& \text { function of } \mathrm{t}_{\mathrm{c}}, \text { and } \\
\mathrm{A}= & \text { drainage area. }
\end{aligned}
$$


The PRM estimates flows from various storm events. In this method the runoff coefficient $\mathrm{C}$ (for return period $\mathrm{n}$ ) is calculated using equation (17.3) according to Australian Rainfall and Runoff (AR\&R):

$$
\mathrm{C}=\mathrm{F}_{\mathrm{i}} \mathrm{C}_{10}
$$

The reasoning behind this two-part runoff coefficient $\left(\mathrm{F}_{\mathrm{i}}\right.$ and $\left.\mathrm{C}_{10}\right)$ is that there is a large resistance to shallower flow on the same basin. Large resistance causes smaller flow and therefore a smaller runoff coefficient. $F_{i}$ is a correction factor for the 10-year runoff coefficient $\left(\mathrm{C}_{10}\right)$ for each storm event. Since the runoff coefficient is an overland discharge coefficient, it varies with various overland flow depths. The values of $\mathrm{F}$ are given in Table 17.2.

Table 17.2 Correction factors of Runoff Coefficient F (CDS Technical Manual, Kohzad).

\begin{tabular}{cc}
\hline Return Period $(\mathrm{y})$ & $\mathrm{F}$ \\
\hline 0.25 & 0.37 \\
0.5 & 0.50 \\
1 & 0.63 \\
2 & 0.75 \\
5 & 0.90 \\
10 & 1.00 \\
25 & 1.10 \\
50 & 1.20 \\
\hline 100 & $1.25-1.30$ \\
\hline
\end{tabular}

The PRM method assumes that each storm event occurs a certain number of times in an average year and is related to exceedance probability. For a specific watershed and known $t_{c}$, the time to peak $t_{p}$ has been roughly correlated to $\mathrm{t}_{\mathrm{c}}$ (Lindeburg, 2006)

$$
t_{p}=0.67 t_{c}
$$

Runoff flow corresponding to n-yr return period can be calculated using Equation 17.2. A Unit Hydrograph can be constructed for each return period storm using the NRCS Unit Hydrograph and Mass Curve Ratios (NRCS, 1969). An illustration of a 6-month and 1-yr hydrograph is shown in Figure 17.3. 


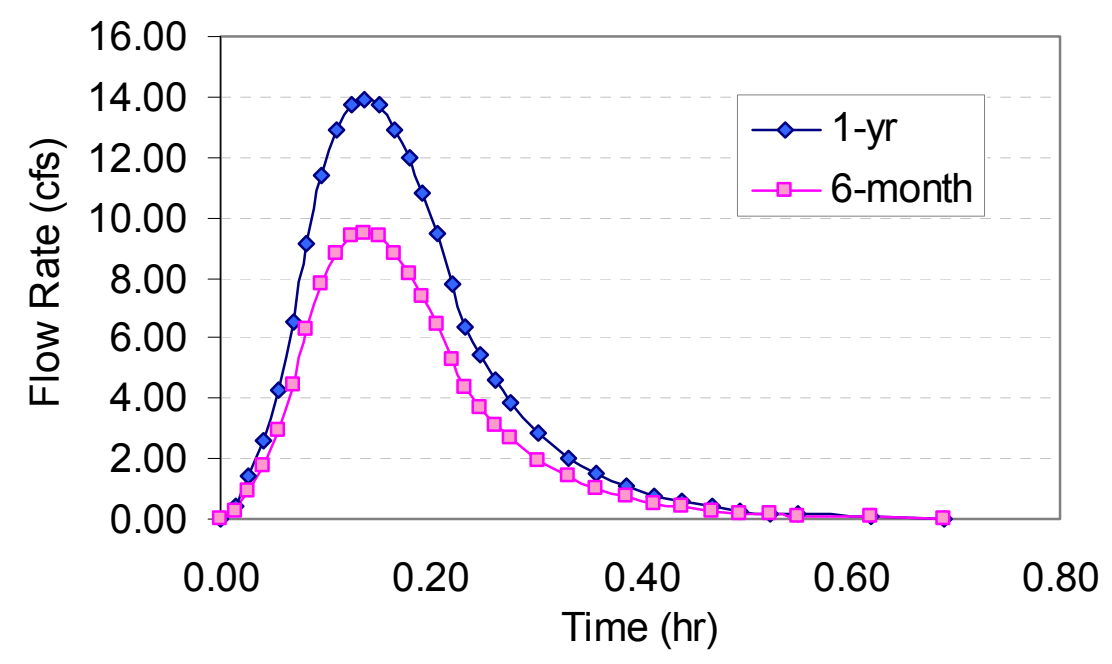

Figure 17.3 SWTU design hydrograph.

Table 17.3 provides the example of performance calculation for the one-yr hydrograph. In this example, a 14-cfs capacity SWTU is selected. The net load removal for a given hydrograph (i.e. one-yr) can be calculated using the performance curve developed for the unit as shown in Figure 17.2.

The total volume treated through SWTU and the average TSS removal are obtained for each hydrograph (1-month, 2-month, up to 12-month). The average annual TSS removal can be derived based on the average removal for each individual return frequency storm. Table 17.4 below shows how the average annual removal is derived.

The PRM method is more precise compared to the rational method which only uses one single intensity and runoff coefficient. It uses hydrographs for $\mathrm{n}$-yr return period of storms to determine the average annual total runoff volume. The runoff flow from each storm event is determined from the hydrograph. The SWTU operates to either treat or bypass the runoff flow based on the system's capacity. The average annual treatment volume is determined by the probability of occurrence of these individual events.

Similar to the rational method, the constraint of the PRM method is that it is not accurate for large drainage areas $>60$ acres (24.28 ha). 
Table 17.3 1-y Hydrograph SWTU performance calculation.

\begin{tabular}{|c|c|c|c|c|c|c|c|c|}
\hline$\stackrel{\mathscr{\Xi}}{\Xi} \cong$ & 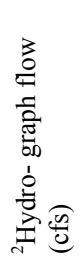 & 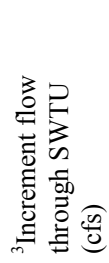 & 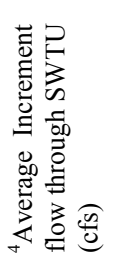 & 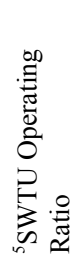 & 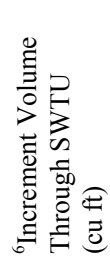 & 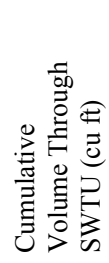 & 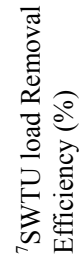 & 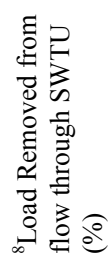 \\
\hline 0.01 & 0.42 & 0.42 & 0.2 & 0.03 & 10 & 10 & 100 & 0.11 \\
\hline 0.03 & 1.39 & 1.39 & 0.9 & 0.10 & 45 & 55 & 99.2 & 0.48 \\
\hline 0.04 & 2.64 & 2.64 & 2.0 & 0.19 & 100 & 155 & 96.8 & 1.05 \\
\hline 0.06 & 4.30 & 4.30 & 3.5 & 0.31 & 172 & 327 & 93.6 & 1.75 \\
\hline 0.07 & 6.53 & 6.53 & 5.4 & 0.47 & 269 & 596 & 89.4 & 2.60 \\
\hline 0.08 & 9.16 & 9.16 & 7.8 & 0.65 & 389 & 985 & 84.3 & 3.56 \\
\hline 0.10 & 11.38 & 11.38 & 10.3 & 0.81 & 509 & 1,494 & 80.1 & 4.42 \\
\hline 0.11 & 12.91 & 12.91 & 12.1 & 0.92 & 602 & 2,096 & 77.2 & 5.04 \\
\hline 0.12 & 13.75 & 13.75 & 13.3 & 0.98 & 661 & 2,757 & 75.6 & 5.41 \\
\hline 0.14 & 13.88 & 13.88 & 13.8 & 0.99 & 685 & 3,442 & 75.3 & 5.59 \\
\hline 0.15 & 13.75 & 13.75 & 13.8 & 0.98 & 685 & 4,127 & 75.6 & 5.61 \\
\hline 0.17 & 12.91 & 12.91 & 13.3 & 0.92 & 661 & 4,788 & 77.2 & 5.53 \\
\hline 0.18 & 11.94 & 11.94 & 12.4 & 0.85 & 616 & 5,404 & 79.0 & 5.28 \\
\hline 0.19 & 10.83 & 10.83 & 11.4 & 0.77 & 565 & 5,969 & 81.1 & 4.97 \\
\hline 0.21 & 9.44 & 9.44 & 10.1 & 0.67 & 503 & 6,472 & 83.8 & 4.57 \\
\hline 0.22 & 7.77 & 7.77 & 8.6 & 0.56 & 427 & 6,898 & 87.0 & 4.03 \\
\hline 0.23 & 6.39 & 6.39 & 7.1 & 0.46 & 351 & 7,250 & 89.7 & 3.41 \\
\hline 0.25 & 5.41 & 5.41 & 5.9 & 0.39 & 293 & 7,542 & 91.5 & 2.90 \\
\hline 0.26 & 4.58 & 4.58 & 5.0 & 0.33 & 248 & 7,790 & 93.1 & 2.50 \\
\hline 0.28 & 3.89 & 3.89 & 4.2 & 0.28 & 210 & 8,000 & 94.4 & 2.1 \\
\hline 0.30 & 2.87 & 2.87 & 3.4 & 0.21 & 335 & 8,335 & 96.4 & 3.50 \\
\hline 0.33 & 2.04 & 2.04 & 2.5 & 0.15 & 244 & 8,579 & 98.0 & 2.59 \\
\hline 0.36 & 1.49 & 1.49 & 1.8 & 0.11 & 175 & 8,754 & 99.0 & 1.88 \\
\hline 0.39 & 1.07 & 1.07 & 1.3 & 0.08 & 127 & 8,881 & 99.8 & 1.37 \\
\hline 0.41 & 0.76 & 0.76 & 0.9 & 0.05 & 91 & 8,971 & 100.4 & 0.99 \\
\hline 0.44 & 0.56 & 0.56 & 0.7 & 0.04 & 65 & 9,037 & 100.8 & 0.71 \\
\hline 0.47 & 0.40 & 0.40 & 0.5 & 0.03 & 48 & 9,084 & 101.1 & 0.52 \\
\hline 0.50 & 0.29 & 0.29 & 0.3 & 0.02 & 34 & 9119 & 101.3 & 0.38 \\
\hline 0.52 & 0.21 & 0.21 & 0.2 & 0.01 & 25 & 9,170 & 101.5 & 0.27 \\
\hline 0.55 & 0.15 & 0.15 & 0.2 & 0.01 & 18 & 9,188 & 101.6 & 0.20 \\
\hline 0.62 & 0.07 & 0.07 & 0.1 & 0.00 & 28 & 9,216 & 101.7 & 0.30 \\
\hline 0.69 & 0.00 & 0.00 & 0.0 & 0.00 & 9 & 9,225 & 101.9 & 0.10 \\
\hline \multicolumn{5}{|c|}{ Total Volume } & 9,199 & \multicolumn{2}{|c|}{ Average Removal } & 84.1 \\
\hline
\end{tabular}

Notes:

$1 \&$ 2. Unit Hydrograph $\mathrm{X}$ axis and $\mathrm{Y}$ axis

3. If hydrograph $\mathrm{Q}<\mathrm{SWTU} \mathrm{Q}_{\text {design }}$, use Q; Otherwise, use SWTU $\mathrm{Q}_{\text {design }}$

4. Average incremental flow

5. Operation ratio $=$ Hydrograph Flow /(SWTU Design Q 14-cfs)

6. Incremental volume $=$ Time $*$ Incremental Flow

7. SWTU removal efficiency obtained from SWTU performance curve

8. Load removal \% $=($ Incremental Volume/Total Volume $) *$ SWTU removal efficiency 
Table 17.4 Example of PRM method for design of flow-through SWTU.

\begin{tabular}{|c|c|c|c|c|c|}
\hline Return & ${ }^{1}$ Period Y & ${ }^{2}$ Flow & $\begin{array}{c}{ }^{3} \mathrm{TSS} \\
\text { Percentage } \\
\text { Captured (R) }\end{array}$ & $\begin{array}{c}{ }^{4} \text { Treated } \\
\text { Flow } \\
\text { Volume }(\mathrm{V})\end{array}$ & $\begin{array}{l}{ }^{5} \text { Annual } \\
\text { Exceedance } \\
\text { Probability }\end{array}$ \\
\hline month / y & $\mathrm{y}$ & $\mathrm{cfs}$ & $\%$ & $\mathrm{cf}$ & $\%$ \\
\hline $1 \mathrm{~m}$ & 0.08 & 2.71 & 98.4 & 1804 & 100.00 \\
\hline $2 \mathrm{~m}$ & 0.17 & 4.48 & 96.1 & 2974 & 99.75 \\
\hline $3 \mathrm{~m}$ & 0.25 & 5.96 & 94.2 & 3962 & 98.17 \\
\hline $4 \mathrm{~m}$ & 0.33 & 7.33 & 92.5 & 4869 & 95.04 \\
\hline $5 \mathrm{~m}$ & 0.42 & 8.50 & 91.1 & 5580 & 90.91 \\
\hline $6 \mathrm{~m}$ & 0.50 & 9.47 & 89.7 & 6292 & 86.47 \\
\hline $7 \mathrm{~m}$ & 0.58 & 10.37 & 88.7 & 6835 & 82.01 \\
\hline $8 \mathrm{~m}$ & 0.67 & 11.20 & 87.6 & 7377 & 77.67 \\
\hline $9 \mathrm{~m}$ & 0.75 & 11.92 & 86.6 & 7920 & 73.64 \\
\hline $10 \mathrm{~m}$ & 0.83 & 12.62 & 85.7 & 8355 & 69.90 \\
\hline $11 \mathrm{~m}$ & 0.92 & 13.27 & 84.9 & 8790 & 66.40 \\
\hline $12 \mathrm{~m}$ & 1 & 13.88 & 84.1 & 9199 & 63.21 \\
\hline \multicolumn{6}{|c|}{${ }^{6}$ Average Annual TSS Removal Efficiency [\%]: 89.2} \\
\hline
\end{tabular}

Notes:

1. Return period in one year $=\mathrm{n} / 12$

2. Flow is calculated using Equation 17.2

3. TSS percent capture is calculated across the unit hydrograph for each return frequency storm (Example of 1-yr removal is shown in Table 17.3.)

4. Treated flow volume is calculated across the unit hydrograph for each return frequency storm (Example of 1-yr removal is shown in Table 17.3.)

5. Annual exceedance probability $=(1-\exp (-1 / \mathrm{Y}))^{\star} 100$

6. Average annual removal $=\frac{\sum_{i=1}^{12}\left(1 / Y_{i}\right) \cdot R_{i} \cdot V_{i}}{\sum_{i=1}^{12}\left(1 / Y_{i}\right) \cdot V_{i}}$

\subsubsection{Probabilistic NRCS Method (P-NRCS)}

The NRCS urban hydrology for small watersheds has wide application for existing and developing urban watersheds. The P-NRCS method computes 
flows for various storm events instead of just one flow as determined by the NRCS method. In this method CN (Curve Number) is held as constant and does not change with respect to rainfall depth or flow depth, because $\mathrm{CN}$ is an interception, infiltration type of coefficient which does not vary much with respect to storm events or flow.

The NRCS runoff depth equation is described in Equation (17.5):

$$
Q=\frac{(P-0.2 S)^{2}}{(P+0.8 S)}
$$

where:

$$
\begin{aligned}
& \mathrm{Q}=\text { runoff depth [in], } \\
& \mathrm{P}=\text { rainfall depth [in], and } \\
& \mathrm{S}=\text { potential maximum retention after runoff begins [in]. }
\end{aligned}
$$

Maximum retention $\mathrm{S}$ is related to the soil cover conditions of the watershed through Curve Number, CN.

$$
S=\frac{1000}{C N}-10
$$

The $\mathrm{CN}$ is a function of the hydrologic soil group, cover type, treatment hydrologic condition and antecedent runoff condition.

Peak discharge can be calculated using the Triangular NRCS method.

The P-NRCS method is used to determine the peak runoff flow rate associated with specific rainfall depth. Performance of the SWTU is then determined in accordance with its operating rate (peak runoff flow/SWTU design capacity). This method can be used for large drainage areas $>60$ acres $(24.28 \mathrm{ha})$. The results from this method for small drainage areas may not converge with the results from the rational method.

The following example illustrates how the P-NRCS method is used to select and design the structure BMP for stormwater treatment. In Table 17.5, a rainfall histogram (depths and frequencies) is obtained from the local rain station database. $\mathrm{CN}$ number is determined for the specific site. Runoff depth $\mathrm{Q}$ is calculated using equation (17.5). The peak discharge rate $Q_{p}$ is determined using triangular method. The water quality flow rate of the BMP is selected to achieve an annual average TSS removal over $80 \%$. As calculated, the annual average removal is $88.55 \%$. 
Table 17.5 Example of P-SCS method for selection and design of flow-through SWTU.

$\begin{array}{lll}\text { Curve Number } & \mathrm{CN} & =98 \\ \text { Maximum retention } & \mathrm{S} & =0.204 \\ \text { BMP design flow rate } & \mathrm{Q}_{\mathrm{BMP}}=7.5 \mathrm{cfs} \\ \text { Time of Concentration } & \mathrm{Tp} & =0.111\end{array}$

Performance data are not available for flow rate exceeding $140 \%$ of the design flow rate. In average performance calculation, no removal credit is given for these events.

\begin{tabular}{|c|c|c|c|c|c|c|c|c|}
\hline \multirow{2}{*}{$\begin{array}{c}\text { Rainfall } \\
\text { Depth } \\
\text { P (in) }\end{array}$} & \multirow{2}{*}{$\begin{array}{c}\% \text { of } \\
\text { Total } \\
\text { Historical } \\
\text { Year } \\
\text { Rainfall }\end{array}$} & \multirow{2}{*}{$\begin{array}{l}\text { Runoff } \\
\text { Q [in] }\end{array}$} & \multicolumn{3}{|c|}{ Flow Rate $=\mathrm{Qp}=0.756 \mathrm{AQ} / \mathrm{Tp}$} & \multirow{2}{*}{$\begin{array}{l}Q_{p} \text { as } \\
\% \text { of } \\
Q_{\text {BMP }}\end{array}$} & \multirow{2}{*}{$\begin{array}{l}\text { BMP TSS } \\
\text { Removal } \\
\text { Eff. (\%) }\end{array}$} & \multirow{2}{*}{$\begin{array}{c}\text { Weighted } \\
\% \\
* \text { TSS } \\
\text { Eff. }\end{array}$} \\
\hline & & & $\begin{array}{c}\text { Qp } \\
(\mathrm{gpm})\end{array}$ & $\mathrm{Qp}(\mathrm{cfs})$ & $\mathrm{Qp}(1 / \mathrm{s})$ & & & \\
\hline 0.02 & $12.2 \%$ & 0.002 & 47.0 & 0.10 & 3.0 & $1.4 \%$ & 100.00 & 12.2 \\
\hline 0.04 & $11.5 \%$ & $3.3 \mathrm{E}-06$ & 0.1 & $1.5 \mathrm{E}-04$ & 4.1E-03 & $0.002 \%$ & 100.00 & 11.5 \\
\hline 0.06 & $11.0 \%$ & 0.002 & 32.8 & 0.07 & 2.1 & $1.0 \%$ & 100.00 & 11.0 \\
\hline 0.08 & $8.9 \%$ & 0.006 & 125.4 & 0.28 & 7.9 & $3.7 \%$ & 100.00 & 8.9 \\
\hline 0.10 & $8.3 \%$ & 0.013 & 264.5 & 0.59 & 16.7 & $7.9 \%$ & 100.00 & 8.3 \\
\hline 0.12 & $7.2 \%$ & 0.022 & 440.0 & 0.98 & 27.8 & $13.1 \%$ & 99.31 & 7.2 \\
\hline 0.14 & $4.8 \%$ & 0.032 & 644.8 & 1.44 & 40.7 & $19.2 \%$ & 98.29 & 4.7 \\
\hline 0.16 & $5.2 \%$ & 0.044 & 873.4 & 1.95 & 55.1 & $25.9 \%$ & 97.10 & 5.0 \\
\hline 0.18 & $3.2 \%$ & 0.056 & 1121.7 & 2.50 & 70.8 & $33.3 \%$ & 95.77 & 3.1 \\
\hline 0.20 & $3.9 \%$ & 0.070 & 1386.5 & 3.09 & 87.5 & $41.2 \%$ & 94.33 & 3.7 \\
\hline 0.25 & $6.0 \%$ & 0.106 & 2104.6 & 4.69 & 132.8 & $62.5 \%$ & 92.79 & 5.6 \\
\hline 0.30 & $3.8 \%$ & 0.145 & 2882.2 & 6.42 & 181.8 & $85.6 \%$ & 88.61 & 3.4 \\
\hline 0.35 & $3.4 \%$ & 0.186 & 3701.9 & 8.25 & 233.6 & $110.0 \%$ & 84.08 & 2.9 \\
\hline 0.40 & $1.5 \%$ & 0.229 & 4552.6 & 10.14 & 287.2 & $135.2 \%$ & 79.32 & 1.2 \\
\hline 0.45 & $1.7 \%$ & 0.273 & 5426.6 & 12.09 & 342.4 & $161.2 \%$ & N/A & 0.0 \\
\hline 0.50 & $1.0 \%$ & 0.318 & 6318.6 & 14.08 & 398.6 & $187.7 \%$ & N/A & 0.0 \\
\hline 0.75 & $4.2 \%$ & 0.551 & 10946.1 & 24.39 & 690.6 & $325.2 \%$ & N/A & 0.0 \\
\hline 0.95 & $1.7 \%$ & 0.743 & 14758.5 & 32.88 & 931.1 & $438.4 \%$ & $\mathrm{~N} / \mathrm{A}$ & 0.0 \\
\hline \multicolumn{8}{|c|}{ Weighted Sum [\% of Total 10-yr Rainfall $*$ BMP TSS Removal Eff $(\%)]=$} & 88.55 \\
\hline
\end{tabular}




\subsubsection{Rational Rainfall Method (RRM)}

The rational rainfall method is an extension of the basic rational method. In this method, runoff flow is determined for each intensity range. A constant runoff coefficient is used. Use of this method requires historical rainfall intensity. The limitation of this method is that it does not provide hydrographs for each storm event. The operation condition of the unit (treatment or bypass condition) is therefore unknown. Table 17.6 illustrates an example of the RRM method. The design flow rate for the selected BMP is assumed to be 14-cfs. Total flow rate in Table 17.6 is calculated from the basic rational method (17.1). The runoff coefficient is assumed to be 0.9 and the watershed area is assumed to be 8 acre (3.24 ha).

Table 17.6 Example of RRM Method for selection and design of flow-through SWTU.

\begin{tabular}{|c|c|c|c|c|c|c|c|}
\hline $\begin{array}{c}\text { Rainfall } \\
\text { Intensity } \\
{[\mathrm{in} / \mathrm{hr}]}\end{array}$ & $\begin{array}{l}{ }^{1} \text { Percent } \\
\text { Rainfall } \\
\text { Volume }\end{array}$ & $\begin{array}{c}\text { Cumulative } \\
\text { Rainfall } \\
\text { Volume }\end{array}$ & $\begin{array}{c}\text { Total } \\
\text { Flowrate } \\
\text { (cfs) }\end{array}$ & $\begin{array}{c}{ }^{2} \mathrm{BMP} \\
\text { Flowrate } \\
\text { (cfs) }\end{array}$ & $\begin{array}{c}{ }^{3} \text { Operating } \\
\text { Rate }(\%)\end{array}$ & $\begin{array}{c}{ }^{4} \mathrm{BMP} \\
\text { Efficiency } \\
(\%)\end{array}$ & $\begin{array}{c}\text { Incrementa } \\
\text { Removal } \\
(\%)\end{array}$ \\
\hline 0.0200 & $0.0 \%$ & $0.0 \%$ & 0.14 & 0.14 & 1.03 & 100.0 & 0.0 \\
\hline 0.0400 & $4.1 \%$ & $4.1 \%$ & 0.29 & 0.29 & 2.06 & 100.0 & 4.1 \\
\hline 0.0600 & $4.3 \%$ & $8.4 \%$ & 0.43 & 0.43 & 3.09 & 100.0 & 4.3 \\
\hline 0.0800 & $4.2 \%$ & $12.6 \%$ & 0.58 & 0.58 & 4.11 & 100.0 & 4.2 \\
\hline 0.1000 & $3.2 \%$ & $15.8 \%$ & 0.72 & 0.72 & 5.14 & 100.0 & 3.2 \\
\hline 0.1200 & $3.2 \%$ & $19.0 \%$ & 0.86 & 0.86 & 6.17 & 100.0 & 3.2 \\
\hline 0.1400 & $2.6 \%$ & $21.6 \%$ & 1.01 & 1.01 & 7.20 & 100.0 & 2.6 \\
\hline 0.1600 & $3.0 \%$ & $24.7 \%$ & 1.15 & 1.15 & 8.23 & 99.7 & 3.0 \\
\hline 0.1800 & $3.1 \%$ & $27.7 \%$ & 1.30 & 1.30 & 9.26 & 99.4 & 3.0 \\
\hline 0.2000 & $2.7 \%$ & $30.4 \%$ & 1.44 & 1.44 & 10.29 & 99.1 & 2.6 \\
\hline 0.2500 & $2.4 \%$ & $32.8 \%$ & 1.80 & 1.80 & 12.86 & 98.4 & 2.4 \\
\hline 0.3000 & $5.4 \%$ & $38.2 \%$ & 2.16 & 2.16 & 15.43 & 97.7 & 5.3 \\
\hline 0.3500 & $5.0 \%$ & $43.2 \%$ & 2.52 & 2.52 & 18.00 & 97.1 & 4.8 \\
\hline 0.4000 & $4.0 \%$ & $47.1 \%$ & 2.88 & 2.88 & 20.57 & 96.4 & 3.8 \\
\hline 0.4500 & $4.9 \%$ & $52.0 \%$ & 3.24 & 3.24 & 23.14 & 95.7 & 4.6 \\
\hline 0.5000 & $3.1 \%$ & $55.1 \%$ & 3.60 & 3.60 & 25.71 & 95.0 & 2.9 \\
\hline 0.7500 & $4.6 \%$ & $59.7 \%$ & 5.40 & 5.40 & 38.57 & 91.5 & 4.3 \\
\hline 1.0000 & $12.3 \%$ & $72.1 \%$ & 7.20 & 7.20 & 51.43 & 88.1 & 10.9 \\
\hline 1.5000 & $10.6 \%$ & $82.7 \%$ & 10.80 & 10.80 & 77.14 & 81.2 & 8.6 \\
\hline 2.0000 & $11.2 \%$ & $93.9 \%$ & 14.40 & 14.00 & 100.00 & 75.1 & 8.2 \\
\hline 2.5000 & $4.8 \%$ & $98.6 \%$ & 18.00 & 14.00 & 100.00 & 75.1 & 2.8 \\
\hline 0.0000 & $1.4 \%$ & $100.0 \%$ & 0.00 & 0.00 & 0.00 & 100.0 & 0.0 \\
\hline \multicolumn{7}{|c|}{ Total Removal } & 82.4 \\
\hline
\end{tabular}

Total removal in the above example is $82.4 \%$.

Notes:

1. Percent rainfall volume is obtained from historical rainfall data. 
2. BMP flow rate: The selected BMP design capacity is 14-cfs. If the runoff flow rate is less than the design flow, the BMP flow rate will be the same as the runoff flow rate. If the runoff flow rate exceeds the design flow rate, the BMP flow rate will be the design capacity.

3. Operating rate $=\mathrm{BMP}$ flow rate/BMP design capacity

4. BMP efficiency is a function of operating flow rate as shown in Figure 17.2 for specific gradation.

\subsection{SWTU Hydraulic Analysis}

The introduction of the stormwater treatment unit will inevitably change the hydraulic grade line (HGL) of the drainage system. A complete hydraulic analysis should be provided for the device. Due to the complexity of internal structures of the SWTU, typically a coefficient of headloss $K_{\text {SWTU }}$ for the unit is provided to evaluate the hydraulic impact in the entire drainage system.

Headloss can be calculated using Equation (17.7)

$$
H_{\text {SWTU }} \approx\left(K_{\text {SWTU }}\right) \frac{\left(V_{d / s}\right)^{2}}{2 g}
$$

If a software program is being used to develop the HGL of the upstream collection system, the values listed above for $K_{S W T U}$ and/or $H_{S W T U}$ can be used as either a headloss factor to be multiplied by the downstream velocity head or simply plug in the headloss value for the SWTU for nodal inputs.

\subsection{Summary}

Structure BMPs are designed to remove pollutants from water quality flow, which is generated from the small storms and associated with the majority of runoff pollution. The flow-through SWTU shall be designed to hydraulically convey the peak flow of the urban drainage system. Definitive hydrology analysis for the watershed is required in order to determine the runoff flow and the water quality flow for the SWTU. Performance requirement should be established and the flow-through SWTU can be sized accordingly.

In summary, the definitive sizing criteria for a structure BMPs (SWTU) should be composed of three components:

1. Determine hydrology method \& water quality flow/volume 
2. Establish performance standards for pollutant of concerns; The performance standard should include specific PSDs for evaluation of performance.

3. Require hydraulic analysis of the selected SWTU in the drainage design

In evaluating and comparing the performance of selected SWTUs or devices, the following factors shall also be taken into consideration: field testing data, third party performance verification, constructability, maintenance of the proposed SWTU.

Implementation and adherence to the above proposed definitive sizing guidelines is relatively a simple endeavor that could initiated throughout North America to improve water quality.

\section{References}

Ball, J.E., and Abustan, I. (1995). "An investigation of particle size distribution during storm events from an urban catchment." The Second International Symposium of Urban Stormwater Management, Melbourne, Australia, 531-535.

Characklis, G. W., and Wiesner, M. R. (1997). "Particles, metals, and water quality in runoff from large urban watershed.” J. Enviro. Engrg., ASCE, 123(8), 753-759.

Drapper, D., Tomlinson, R. and Williams, P. (2000). "Pollutant concentrations in road runoff: Southeast Queensland case study.” J. Enviro. Engrg., ASCE, 126(4), 313-320.

De Ridder, S., Sykes, M., Tetreault H. (2007) SHIVER 'ME CHAMBERS! The Effect of Water Temperature on the Performance of Hydrodynamic Stormwater Treatment Devices, StormCon 2007 Proceedings

Kobringer, N. P. (1984). "Volume I. Sources and migration of highway runoff pollutants.” FHWA/RD-84/057, Federal Highway Administration, Rexnord, EnvironEnergy Technology Center, Milwaukee, WI.

Li, Y., Lau, S.L., Kayhanian, M., Stenstrom, M. (2005). "Particle Size Distribution in Highway Runoff”, J. Enviro. Engrg., ASCE, 131(9), 1267-1276.

Metcalf \& Eddy (2003), "Wastewater Engineering Treatment and Reuse" Fourth Edition

Sansalone, J., and Buchberger, S. (1997). "Partitioning and first flush of metals in urban roadway storm water.” J. of Envir. Engrg., 123(2), 134-143.

Sansalone, J., Koran, J., Smithson, J. and Buchberger, S. (1998). "Physical Characteristics of urban roadway solids transported during rain event" J. of Envir. Engrg., 124(5), 427-440.

Sartor, J.D., and Boyd G.B. (1972). Water pollution aspects of street surface contaminants. EPA-R2-72-081. 236.

Shaheen, D. (1975). Contribution of Urban Roadway Usage to Water Pollution. EPA-600/2-75-004. 